\title{
Ações de ecoeficiência para melhoria do desempenho no transporte rodoviário de produtos perigosos
}

\author{
Ilton Curty Leal Junior ${ }^{1}$ e Marcio de Almeida D’Agosto ${ }^{2}$
}

\begin{abstract}
Resumo: O modo rodoviário é o mais utilizado para a movimentação de etanol no Brasil e seu desempenho, se comparado aos demais modos, é inferior em termos de ecoeficiência para o produto em questão. Diante disto, este trabalho propõe a avaliação da implantação de ações que melhorem os resultados econômicos e ambientais do transporte rodoviário. Inicialmente comparou-se o desempenho entre as várias alternativas modais. Após isso, foi realizada uma nova avaliação considerando ações para a melhoria de ecoeficiência como aquelas relacionadas à redução no consumo de combustível e redução no número de acidentes, utilização de biodiesel, e alterações nos valores de frete. Os resultados mostram que o modo rodoviário, se comparado com outras nove alternativas intermodais, pode sair do último lugar em desempenho para o quarto lugar. DOI:10.4237/transportes.v20i3.563.
\end{abstract}

Palavras-chave: ecoeficiência, transporte rodoviário, produtos perigosos.

\begin{abstract}
The road transport is the most widely used for the movement of ethanol in Brazil and its performance compared to other modes, is lower in terms of eco-efficiency for this product. Based on this problem, this paper proposes the evaluation of the implementation of actions to improve the economic and environmental outcomes of road transport. We initially compared the performance considering ten alternatives, including the road transport. After that, a new evaluation was performed considering improving eco-efficiency with actions that permit a reduction in fuel consumption and number of accidents, use of biodiesel and changes in the freight revenue. The results show that the road transport, if compared with nine other intermodal alternatives, can improve its performance, leaving the last position to the fourth position in the eco-efficiency ranking.
\end{abstract}

Keywords: ecoefficiency, road transport, hazardous products.

\section{INTRODUÇÃO}

O transporte de carga no Brasil concentra-se no modo rodoviário que pode não ser o mais adequado do ponto de vista econômico e ambiental, se comparado com os demais. $\mathrm{O}$ transporte de produtos perigosos acompanha esta distorção encontrada na matriz de transportes brasileira o que contribui para a redução de competitividade do setor e potencializa a ocorrência de impactos ao meio ambiente.

Proposto por Leal Jr e D’Agosto (2011), o Método de Escolha Modal (MEM) considera aspectos relacionados à avaliação de desempenho para auxiliar a tomada de decisão quanto à escolha do modo de transporte, dentre os quais se destaca o conceito de ecoeficiência, por considerar a eficiência econômica e ambiental conjuntamente (Frota Neto et al, 2009). O MEM permite o emprego de uma estrutura para escolha modal que utilize as medidas de ecoeficiência, o que propicia uma gestão diferencial na operação de transportes para as empresas que valorizam as questões ambientais (Leal Jr e D’Agosto, 2011).

Para a movimentação de produtos como o etanol produzido na região centro-sul do Brasil predomina o transporte rodoviário e uma análise efetuada por meio do MEM mostrou o baixo desempenho em termos de ecoeficiência deste modo, se comparado a alternativas intermodais (Leal Jr, 2010). Por outro lado, as alternativas modais apresentadas por Leal Jr (2010), como de melhor ecoeficiência não dis-

\footnotetext{
${ }^{1}$ Ilton Curty Leal Junior, Departamento de Administração e Administração Pública, Universidade Federal Fluminense, Volta Redonda, RJ, Brasil. (email: iltoncurty@gmail.com).

${ }^{2}$ Marcio de Almeida D'Agosto, Programa de Engenharia de Transportes, Centro de Tecnologia, Universidade Federal do Rio de Janeiro, Rio de Janeiro, RJ, Brasil. (e-mail: dagosto@pet.coppe.ufrj.br).
}

Manuscrito recebido em 11/3/2012 e aprovado para publicação em 2/10/2012. Este artigo é parte de TRANSPORTES v. 20, n. 3, 2012. ISSN: 2237-1346 (online). DOI:10.4237/transportes.v20i3.563. põem de suficiente infraestrutura para atender a demanda por transporte de etanol, forçando aos embarcadores a utilizar veículos rodoviários para esta atividade.

Neste contexto, o presente trabalho baseia-se na seguinte pergunta para seu desenvolvimento: Dada a grande utilização do modo rodoviário para o transporte de etanol e as limitações para utilização de alternativas que empreguem outros modos, como melhorar a ecoeficiência daquele modo por meio de ações de fácil implantação?

Para responder a esta questão, este trabalho tem por objetivo aplicar o Método de Escolha Modal (MEM), considerando medidas de ecoeficiência para o caso do transporte de etanol produzido na região centro-sul do Brasil com destino a um porto para exportação. Com base no desempenho atual do modo rodoviário, ações que influenciam na ecoeficiência são utilizadas para verificar a melhoria frente às demais alternativas modais.

Para este estudo foram levantados os atributos para a avaliação de desempenho das alternativas de transporte de etanol com e sem as ações de ecoeficiência no transporte rodoviário. Para a quantificação dos atributos foram estabelecidos indicadores e medidas cujos valores foram agregados para posterior análise que contou com a aplicação de uma técnica de apoio multicritério à decisão conhecida como Análise Relacional Grey, sendo possível ranquear o desempenho das alternativas analisadas. Os resultados mostram que ao incluir ações ecoeficientes na análise, o desempenho das alternativas o transporte rodoviário com o pior desempenho no cenário atual, apresenta melhorias em relação aos demais.

A partir desta introdução, este artigo se divide em mais 6 seções. A segunda e terceira tratam do contexto do transporte de produtos perigosos no Brasil e dos conceitos em que se baseiam este artigo. A seção 4 apresenta os procedimentos e técnicas empregadas, incluindo uma breve des- 
crição do método de escolha modal e como o mesmo se adéqua aos conceitos de ecoeficiência. A quinta seção apresenta o desenvolvimento do trabalho e descreve um estudo de caso realizado para a aplicação proposta, com posterior análise dos resultados. A sexta seção mostra as principais conclusões, limitações e proposições para novos estudos e é seguida pela última seção que lista as referências bibliográficas utilizadas para desenvolvimento do artigo.

\section{TRANSPORTE DE PRODUTOS PERIGOSOS NO BRASIL}

Conforme CETESB (2009), os produtos perigosos são transportados em todos os modos disponíveis (ferroviário, rodoviário, aquaviário, dutoviário e aéreo) e o mais adequado varia com as características da rede logística, devendo ser determinado por atributos específicos para a avaliação de desempenho do transporte, pela disponibilidade de cada modo e da infraestrutura necessária.

No Brasil e no mundo, o transporte de produtos perigosos está concentrado nos líquidos inflamáveis, principalmente no petróleo, seus derivados e combustíveis líquidos de fontes renováveis (Leal Jr., 2010). Observa-se que o modo rodoviário é responsável por grande parte da movimentação de carga, seja pelas próprias características da atividade de transporte que envolve a distribuição física em áreas urbanas ou pela falta de infraestrutura para integração com outros modos.

No Brasil, a movimentação de produtos perigosos concentra-se na Região Sudeste por estar associada à região de maior produção e consumo (CETESB, 2009). Dos poucos estudos e dados nacionais sobre transporte de produtos perigosos encontram-se os referentes ao Estado de São Paulo, maior produtor e consumidor da região citada. Admite-se, portanto, que o que se verifica em São Paulo poderia ser considerado como um caso extremo da realidade brasileira e assim sendo, representar uma situação crítica a ser estudada.

A quantidade de leis, normas e parâmetros técnicos nacionais e internacionais para o transporte de produtos perigosos o tornam mais complexo, do ponto de vista operacional e gerencial, o que pode intervir em questões econômicas e financeiras para os produtores e transportadores. No caso de produtos perigosos, além dos impactos ambientais tradicionais ocasionados pelos transportes (consumo de energia não renovável, emissão de gases de efeito estufa, poluição atmosférica, descarte de lubrificantes, etc.) a ocorrência de acidentes pode gerar impactos ambientais, uma vez que um produto derramado pode poluir solo, água e ar e causar danos às pessoas e propriedades.

\section{AVALIAÇÃO DE DESEMPENHO, ECOEFICIÊNCIA E ESCOLHA MODAL}

As organizações buscam excelência em suas atividades, objetivando a conquista de novos mercados e maior qualidade em seus produtos e serviços. Nesses termos, é destacável a contribuição da avaliação de desempenho para as organizações. Os sistemas de avaliação de desempenho, nas organizações, pretendem estabelecer maneiras de acompanhar os processos ou as atividades para verificar se os mesmos estão atendendo às necessidades e expectativas dos interessados e para fornecer informações adequadas a fim de que sejam tomadas decisões relativas a ações de prevenção e manutenção ou correção de tais processos ou atividades, de forma que se atinjam objetivos organizacionais.

Antoniolli (2003) cita que a necessidade do gerenciamento de desempenho cada vez mais efetivo tem impulsionado as empresas a desenvolverem formas de monitorá-lo e avaliá-lo. De acordo com Quintão et al. (2003), a avaliação de desempenho é considerada complexa e quando mal conduzida não apresenta resultado concreto quando o objeto de análise é o desempenho de uma atividade ou um processo específico como o transporte.

Neste contexto, o conceito de ecoeficiência para o estabelecimento de medidas de desempenho considera não apenas o tradicional enfoque econômico-financeiro, mas também a atual abordagem socioambiental, uma vez que essa abordagem enfoca a utilização adequada de recursos materiais e energéticos, com o sentido de se reduzir custos e/ou de se maximizar lucros. A ecoeficiência é a habilidade de simultaneamente atingir os objetivos de produção e custo com qualidade e desempenho, reduzir impactos ambientais e conservar recursos naturais. A ecoeficiência permite às empresas tornarem-se mais responsáveis do ponto de vista ambiental e mais lucrativas no âmbito econômico, incentivando-as à inovação e à competitividade (WBCSD, 2000).

$\mathrm{O}$ conceito de ecoeficiência promove uma contribuição à área de avaliação de desempenho em transportes por meio de uma abordagem específica que a princípio está principalmente associada ao contexto dos sistemas de produção, sendo perfeitamente possível adequá-la ao contexto do transporte de carga.

A literatura pesquisada mostra que a utilização do conceito de ecoeficiência na avaliação do desempenho de transporte pode trazer vantagem para transportadores, usuários e sociedade, contribuindo para o desenvolvimento sustentável. Com levantamento na literatura especializada, Bowersox e Closs (2001), Chopra e Meindl (2003), Christopher (1997), Dreyer (2000), Fontana et. al. (2009), Gonçalves e Costa (2009), Granemann e Gartiner (2000), Lambert e Pohlen (2001), Leal Jr e Macedo (2004), Martins et. al. (2005), Mello et.al. (2009), Oliveira e Cury (2004), Pacheco et al. (2008), Pereira (1983), Pereira Neto (2001), Pezerico (2002), Santana Filho (1984), SCC (2002), Silva e Leal Jr (2009), Neves (2000), Tuzkaya e Onut (2008), é possível perceber que ao se avaliar o desempenho sob o enfoque tradicional, costuma-se privilegiar aspectos econômico-financeiros em detrimento dos socioambientais.

Esse viés econômico-financeiro acontece, pois tradicionalmente as organizações têm a ideia de que considerar questões ambientais aumenta os custos, o que prejudica o desempenho econômico. O conceito de ecoeficiência vem ao encontro desses conceitos, mostrando que é possível combinar as ideias antagônicas de desempenho econômicofinanceiro e de redução de influências ambientais.

A combinação eficiente entre as atividades econômicas e o meio ambiente para se alcançar a sustentabilidade (Odum, 1998) parece ilusória na prática, em particular quando se considera ganho financeiro e reduções das influências ambientais (Walley e Whitehead, 1994).

No setor de transporte de cargas, é possível verificar essa aparente contradição sendo possível aplicar o conceito de sustentabilidade e conciliar as questões econômicas com as ambientais. Um transportador pode, por exemplo, melhorar 
o desempenho de seus veículos, reduzindo consumo de combustível, contribuindo para menores emissões de $\mathrm{CO} 2 \mathrm{e}$ consequentemente reduzindo seus custos.

Observando-se as referências pesquisadas, BCDSD Portugal (2007 apud Salgado, 2007), Becken (2007), BP (2003), Cantarino (2003), CEBDS (2008), D’Agosto e Ribeiro (2004), English et al. (2006), EPA (2002), Frota Neto et al. (2009), GRI (2000), Holliday (2003), Jollands et al. (2004), Leyen (2008), Michelini et al. (2004), Michelsen et al. (2005), Mickwitz et al. (2005), Petrobras (2003), Pinho, Catanzano e Candeira (2011), Saari et al. (2006), Santos (2007), Schmidt e Schwegler (2008), Tsoulfas e Pappis (2005), Verfaillie e Bidwell (2000), WBCSD (2000), percebe-se a importância e atualidade do tema. Verifica-se uma forte aplicação dos conceitos de ecoeficiência genericamente no contexto da cadeia de suprimentos e em processos produtivos.

Outras referências abordam a utilização da ecoeficiência especificamente nos transportes como é o caso de Cheon et al. (2009), D'Agosto e Ribeiro (2004), Hendriks e Jager (2001), Martins et al. (1999), Salgado (2007), Silva (2004), VALE (2007), Varig (2002).

Com o intuito de melhor atender à demanda, as organizações avaliam novas formas de transportar, o que pode envolver a escolha de diferentes modos de transporte ou suas combinações, na forma de transporte intermodal ou multimodal. Essa escolha pode interferir fortemente na forma como a organização atuará no mercado, devendo estar alinhada com uma visão estratégica e de longo prazo o que inclui, na visão moderna, considerar questões relacionadas ao meio ambiente. $\mathrm{O}$ desenvolvimento de ferramentas que auxiliem nessa escolha é fundamental para a estratégia organizacional, sendo que a avaliação de desempenho do serviço de transporte pode ser empregada para isso (Ballou, 2001; Novaes, 2004; Manheim, 1980; Morlok, 1980; D'Agosto, 1999).

\section{PROCEDIMENTOS E TÉCNICAS EMPREGADOS}

Para o estudo proposto neste artigo são aplicadas duas ferramentas combinadas. O Método de Escolha Modal (MEM), que se baseia em medidas de ecoeficiência, e uma técnica de auxílio multicritério conhecida como Análise Relacional Grey.

\subsection{Método de Escolha Modal (MEM) e as medidas de ecoeficiência}

O MEM (Leal Jr e D’Agosto, 2011) detalha o processo de tomada de decisão em transportes e sua concepção se aplica à escolha modal de transporte de uma forma geral. Este método é essencialmente dinâmico e seus resultados podem ser revistos ao longo do tempo, pois o resultado final pode ser utilizado para alimentar um novo ciclo de avaliação. $O$ MEM é composto de 7 etapas conforme Figura 1 e todos os detalhes do método podem ser acessados em Leal Jr e D’Agosto (2011).

A necessidade de se mensurar e quantificar a ecoeficiência resulta na necessidade de se utilizar medidas de ecoeficiência. Os indicadores de ecoeficiência podem ser gerais e usados para todas as atividades de negócios, ou específicos para um determinado setor (WBCSD, 2000). No estabelecimento de indicadores têm-se aqueles relacionados a pro- dutos e/ou serviços produzidos ou vendidos e os referentes às influências ambientais globais. Da mesma forma, ainda podem ser estabelecidos indicadores específicos, onde cada empresa avalia o seu próprio negócio e determina seus próprios indicadores. Estes são menos abrangentes na sua aplicabilidade, porém, não são necessariamente menos importantes que os de aplicação geral.

A utilização dos indicadores de ecoeficiência gera medidas específicas baseadas na relação de valor do produto ou serviço com a influência ambiental e que são representadas pela Equação 1, conforme WBCSD (2000).

$$
\text { Ecoeficiência }=\frac{\text { Valor do produto ou serviço }}{\text { Influências ambientais }}
$$

Com base neste conceito podem ser propostas medidas de ecoeficiência para o transporte de carga, para serem utilizadas no processo de avaliação de desempenho e escolha modal. Sugere-se que o avaliador escolha apenas um indicador de valor do serviço como numerador, combinando-o com as influências ambientais mais representativas.

\subsection{Análise Relacional Grey (GRA)}

A teoria de sistemas grey foi proposta por Julong Deng em 1982 com o intuito de evitar os problemas inerentes dos métodos estatísticos e requer uma quantidade limitada de dados para estimar o comportamento de um sistema incerto (Wen, 2004).

A teoria grey tem sido aplicada nos mais variados campos de pesquisa, como produção, sistemas sociais, ecologia, economia, geografia, tráfego, gerenciamento, educação etc. Foca em situações em que há a incerteza, variedade de dados de entrada, dados discretos e informações insuficientes para a tomada de decisão.

A teoria grey parte do princípio que existem informações a respeito de um sistema que são "claras" e podem ser medidas e encontradas facilmente e outras que são cinzentas ou não são bem definidas e são incompletas.

A análise relacional grey (GRA - Grey Relational Analisys) integra a teoria de sistemas grey (Deng, 1989; Liu e Lin, 2006). É um método utilizado para determinar o grau de relacionamento entre uma observação referencial com observações levantadas, objetivando estabelecer um grau de proximidade com o estado meta, ou seja, o resultado desejado.

Segundo Bischoff (2008), a GRA utiliza a informação do sistema grey para comparar dinamicamente cada fator quantitativamente, baseado no nível de similaridade e de variabilidade entre todos os fatores para estabelecer a sua relação. É um método para analisar o grau de relacionamento para sequencias discretas.

Seja um conjunto de observações $\left\{x_{0}{ }^{(o)}, x_{1}{ }^{(o)}, \ldots, x_{m}{ }^{(o)}\right\}$, onde $x_{0}{ }^{(o)}$ é uma observação referencial e $x_{1}{ }^{(o)}, x_{2}{ }^{(o)}, \ldots, x_{m}{ }^{(o)}$ são observações originais a serem comparadas. Cada observação $x_{i}$ possui $n$ medidas que são descritas sob a forma de séries $x_{i}^{(o)}=\left\{x_{i}^{(o)}(k), \ldots, x_{m}{ }^{(o)}(n)\right\}$, onde cada componente dessa série, antes de qualquer operação, é normalizado da forma a seguir.

Se o resultado desejável da medida for o maior possível para se alcançar melhores desempenhos deve-se utilizar a Equação 2. Cita-se como exemplo um conjunto de alternativas que sejam avaliadas pela sua receita, onde a alternativa de maior receita seja a de melhor resultado. 


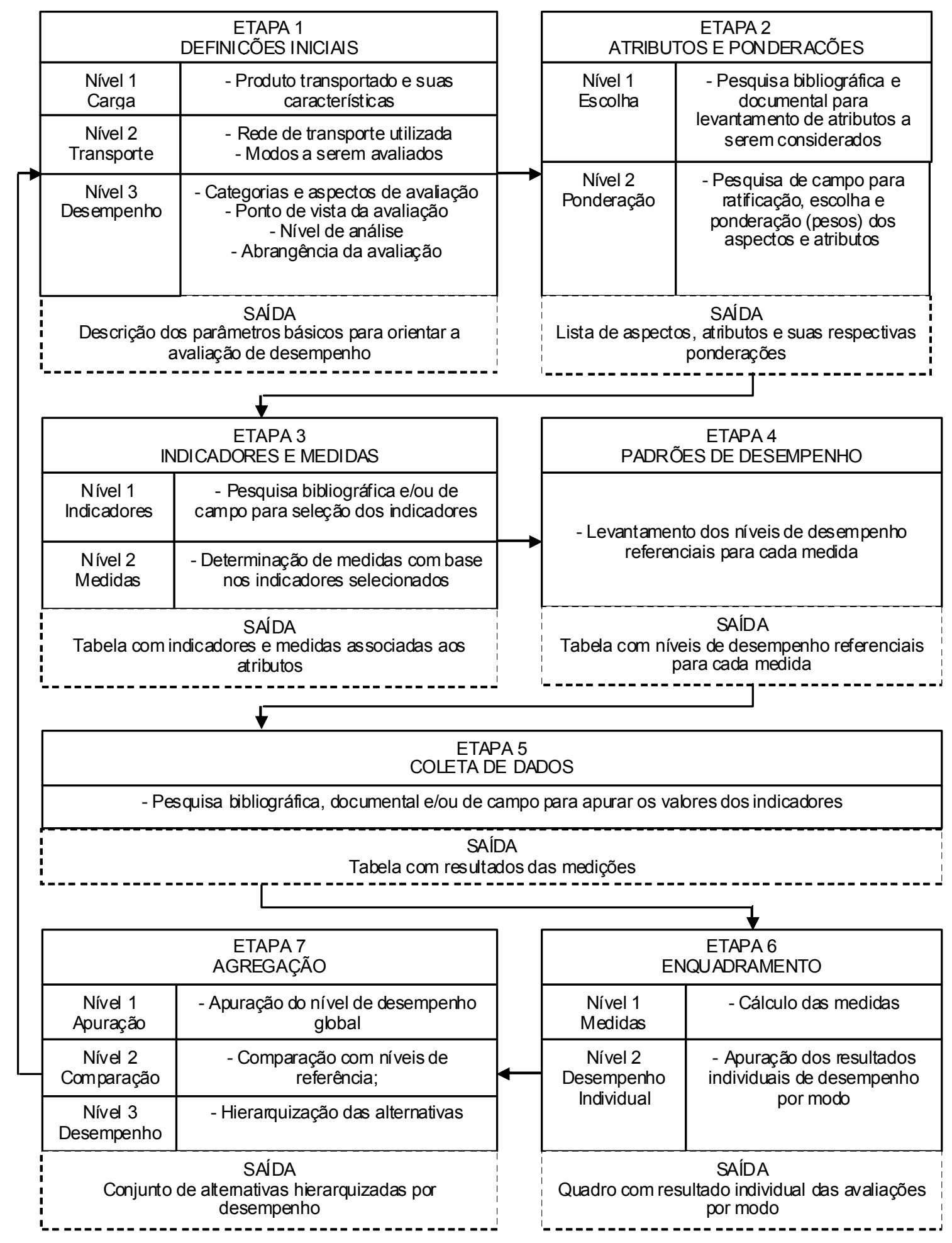

Figura 1. MEM com procedimento de avaliação de desempenho em transporte [Fonte: Leal Jr e D’Agosto (2011)]

$$
x_{i}^{\prime}(k)=\frac{x_{i}^{(o)}(k)-\min _{\forall i}\left(x_{i}^{(o)}(k)\right)}{\max _{\forall i}\left(x_{i}^{(o)}(k)\right)-\min _{\forall i}\left(x_{i}^{(o)}(k)\right)}, \quad i: 0 . . \mathrm{m}, \quad k: 1 . . \mathrm{n}
$$

Se, contrário a situação anterior, for desejável que a medida tenha o menor valor possível para se obter um melhor desempenho deve-se utilizar a Equação 3. Cita-se como exemplo um conjunto de alternativas cujas medidas para avaliação estejam baseadas no custo. Neste caso, quanto menor for o custo, melhor será o desempenho da alternati- va.

$$
x_{i}^{\prime}(k)=\frac{\max _{\forall i}\left(x_{i}^{(o)}(k)\right)-x_{i}^{(o)}(k)}{\max _{\forall i}\left(x_{i}^{(o)}(k)\right)-\min _{\forall i}\left(x_{i}^{(o)}(k)\right)}, \quad i: 0 . . \mathrm{m}, \quad k: 1 . . \mathrm{n}
$$

em que: $x_{i}^{\prime}(k)$ é o valor normalizado de uma medida $k$ para uma observação original $x_{i}^{\left({ }^{\circ}\right)}$.

A série cujos atributos normalizados são os melhores possíveis e representa o estado desejado para qualquer série é representada por $x_{0}$, sendo os valores da mesma igualados 
a 1. Essa é uma abordagem que propõe um contorno para os muitos casos em que a medida de referência não é facilmente encontrada ou difícil de ser calculada.

Após a normalização dos dados de cada série, calculamse os coeficientes relacionais grey $\gamma$ (Equação 4).

$$
\begin{aligned}
& \gamma\left(x_{0}^{\prime}(k), x_{i}^{\prime}(k)\right)= \\
& =\frac{\min _{\forall i} \min _{\forall k}\left|x_{0}(k)-x_{i}(k)\right|+\zeta \max _{\forall i} \max _{\forall k}\left|x_{0}(k)-x_{i}(k)\right|}{x_{0}(k)-x_{i}(k)+\zeta \max _{\forall i} \max _{\forall k}\left|x_{0}(k)-x_{i}(k)\right|}
\end{aligned}
$$

em que $\zeta \in[0,1]$ assume, em geral, o valor 0,5 , sendo útil somente para diferenciar os elementos da série e não influenciando na ordenação final das séries (Deng, 1989).

Segundo Wen (2004), dentro do intervalo de $\zeta$, pode-se atribuir qualquer valor entre 0 e 1, mas usualmente adota-se 0,5. É possível demonstrar que a mudança no valor de $\zeta$ não altera o ranking dos graus de relacionamento grey $(\mathrm{Zu}-$ o, 1995). Se o valor de $\zeta$ for próximo de zero, haverá um maior distanciamento das alternativas em termos de desempenho, porém, a ordem de desempenho não mudará. Se o valor de $\zeta$ se aproximar de 1 , as distâncias entre as alternativas diminuirá, não alterando a ordenação das mesmas quanto ao desempenho.

Os coeficientes relacionais expressam a similaridade entre as respectivas medidas associadas à série padrão e às séries comparativas e refletem o quanto cada uma está distante de sua respectiva na série padrão.

Depois de estabelecidos os coeficientes relacionais grey, é necessário que se estabeleçam os graus de relacionamento grey $\left(\Gamma_{\mathrm{i}}\right)$ para cada série (Deng, 1989), conforme Equação 5 , que é a média aritmética simples dos coeficientes relacionais grey para cada alternativa.

$$
\Gamma_{i}=\sum_{k=1}^{n} \beta_{k} \gamma_{i}\left(x_{0}^{\prime}(k), x_{i}^{\prime}(k)\right)
$$

em que $\beta_{\mathrm{k}}$ é o peso de cada atributo e $\sum_{j=1}^{n} \beta_{k}=1$.

\section{DESENVOLVIMENTO - ESTUDO APLICADO}

Para o desenvolvimento deste artigo foi realizado um estudo aplicado que compara o desempenho dos modos de transporte no cenário atual e posteriormente o desempenho do modo rodoviário com a implementação de ações de melhoria de ecoeficiência.

\subsection{Estudo aplicado - descrição}

Propõe-se a escolha entre os vários modos de transportes e suas combinações utilizadas para o etanol produzido na região centro-sul do Brasil e que se destina à exportação.

A partir de TRANSPETRO (2008) identificou-se a rede para transporte do etanol e as alternativas modais (Figura 2) onde se encontram os terminais existentes e projetados, a hidrovia Tietê-Paraná e o projeto do alcoolduto que liga Senador Canedo em Goiás ao Porto de São Sebastião em São Paulo. Foram consideradas as redes ferroviária e rodoviária atuais, com base em ANTT (2008). Para exportação considera-se o porto de São Sebastião, pois possui um terminal da TRANSPETRO e tem capacidade de ser o principal terminal exportador de etanol (Rodrigues, 2007). Foram ainda considerados veículos rodoviários bitrem tanque com capacidade para $45 \mathrm{~m}^{3}$, composição ferroviária com 100 vagões-tanque com capacidade de $103 \mathrm{~m}^{3}$ cada, comboio hidroviário com 4 chatas com capacidade de $1270 \mathrm{~m}^{3}$ cada e alcoolduto com capacidade de $33.000 \mathrm{~m}^{3} / \mathrm{dia}$.

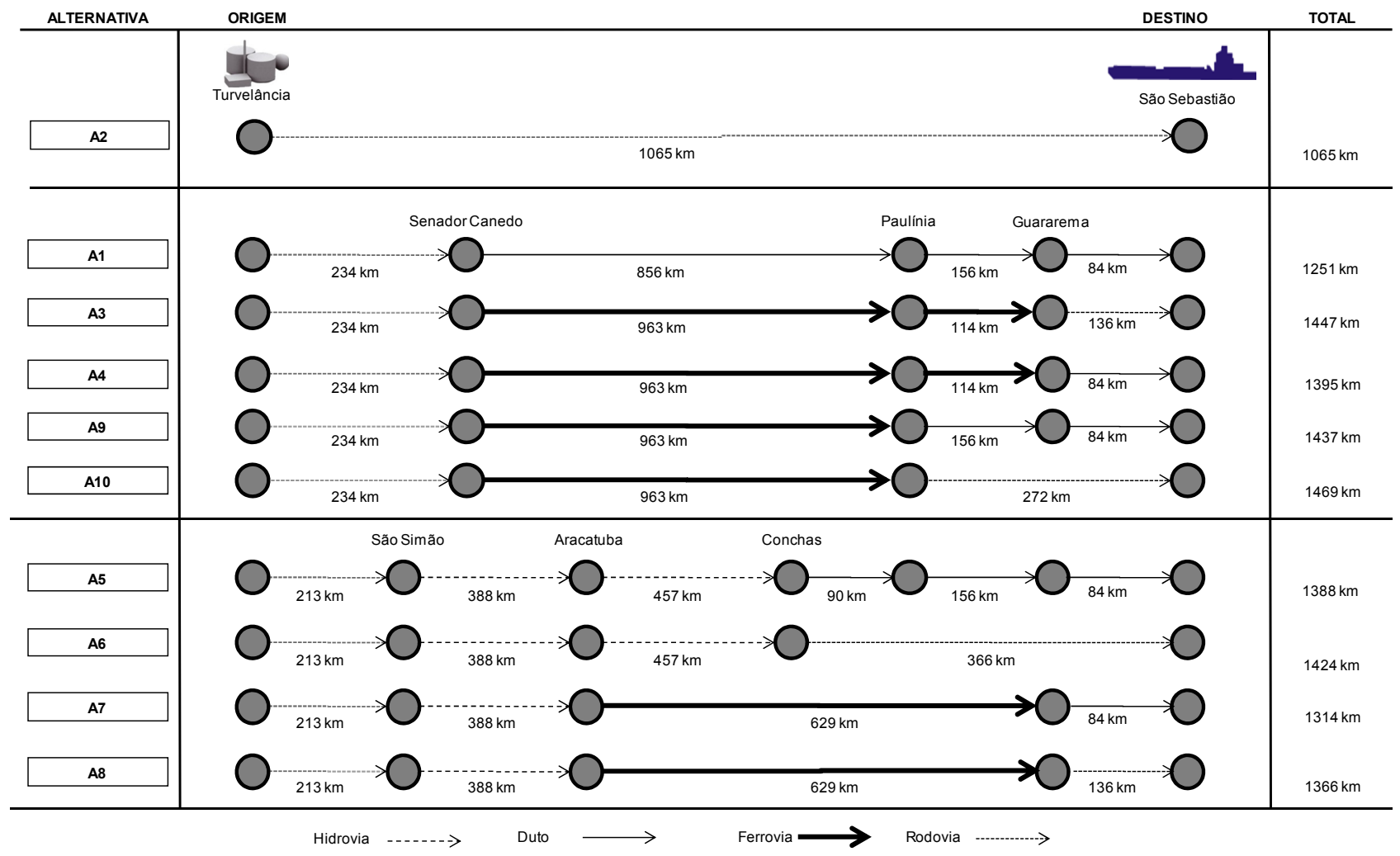

Figura 2. Rede para escoamento de etanol do centro-sul do Brasil para exportação. [Fonte: Elaboração própria a partir de Rodrigues (2007), Odebrecht (2007), CETESB (2009) Lopes e Ferreira (2004), TRANSPETRO (2008a), ANTT (2008)] 
Tabela 1. Medidas de ecoeficiência

\begin{tabular}{|c|c|c|c|c|c|}
\hline & M1 & $M 2$ & M3 & M4 & M5 \\
\hline & $\begin{array}{l}R F R / C T A \\
\text { (receita de frete } \\
\text { recebida }- \text { RFR; } \\
\text { custo total de } \\
\text { acidentes }-C T A \text { ) } \\
\text { [Adimensional] }\end{array}$ & $\begin{array}{l}R F R / C T E \\
\text { (receita de frete } \\
\text { recebida }- \text { RFR; } \\
\text { consumo total de } \\
\text { energia }- \text { CTE) } \\
{[U S \$ / M J]}\end{array}$ & $\begin{array}{l}\text { RFR/CO2E } \\
\text { (receita de frete } \\
\text { recebida - RFR; } \\
\text { emissão de gases } \\
\text { de efeito estufa- } \\
C O 2 E \text { ) } \\
{[U S \$ / \mathrm{kg}]}\end{array}$ & $\begin{array}{l}R F R / P A E \\
\text { (receita de frete rece- } \\
\text { bida - RFR; emissão } \\
\text { de poluentes atmosfé- } \\
\text { ricos - PAE) } \\
{[U S \$ g]}\end{array}$ & $\begin{array}{l}\text { RFR/QOMD } \\
\text { (receita de frete } \\
\text { recebida-RFR; } \\
\text { óleo lubrificante } \\
\text { descartado- } \\
\text { QOMD) } \\
{[U S \$ / l]}\end{array}$ \\
\hline Alternativas & $x_{i}^{(0)}(1)$ & $x_{i}^{(0)}(2)$ & $x_{i}^{(0)}(3)$ & $x_{i}^{(0)}(4)$ & $x_{i}^{(0)}(5)$ \\
\hline A1 & 32,03 & 0,19 & 3,49 & 41,27 & 5404,63 \\
\hline $\mathrm{A} 2$ & 50,17 & 0,06 & 0,82 & 10,38 & 1272,26 \\
\hline A3 & 107,07 & 0,12 & 1,70 & 20,70 & 2401,47 \\
\hline A4 & 103,90 & 0,14 & 1,98 & 23,81 & 2733,34 \\
\hline A5 & 73,12 & 0,16 & 2,30 & 28,14 & 2214,44 \\
\hline A6 & 97,30 & 0,10 & 1,37 & 17,18 & 1633,57 \\
\hline A7 & 121,37 & 0,16 & 2,21 & 26,77 & 2630,57 \\
\hline A8 & 124,14 & 0,13 & 1,83 & 22,51 & 2307,42 \\
\hline A9 & 82,21 & 0,15 & 2,12 & 25,42 & 2941,54 \\
\hline A10 & 97,74 & 0,11 & 1,56 & 19,19 & 2251,63 \\
\hline$x_{0}{ }^{(0)}(j)$ & 124,14 & 0,19 & 3,49 & 41,27 & 5404,63 \\
\hline
\end{tabular}

Para aplicação o ponto de origem é a cidade de Turvelândia - GO, que está entre as 10 maiores produtoras de etanol do Brasil (Rodrigues; 2007). Sua escolha se deve à posição geográfica que permite a utilização das várias alternativas modais para aplicar o MEM. Foi estabelecido que todo o etanol produzido é coletado via modo rodoviário até a chegada em um terminal da rede apresentada, por ser a prática adotada pela maioria dos produtores. O modo rodoviário é o mais utilizado para o transporte de etanol respondendo por $96 \%$ da movimentação (Rodrigues, 2007).

Conforme prevê o MEM, foram selecionados os aspectos, atributos e indicadores para o estabelecimento das medidas de desempenho de acordo com Leal $\mathrm{Jr}$ e D’Agosto (2011) que foram calculadas conforme Equação 1, sendo que como numerador foi utilizado o indicador receita de frete recebida pelos transportadores - RFR (em dólares) e no denominador os indicadores de influência ambiental: (i) custo total de acidentes - CTA (em dólares), (ii) consumo total de energia - CTE (em Mega Joules), (iii) emissão de gases de efeito estufa - $\mathrm{CO} 2 \mathrm{E}$ (em quilogramas), (iv) emissão de poluentes atmosféricos - PAE (em gramas) e (v) óleo lubrificante descartado - QOMD (em litros). Esses indicadores foram obtidos por meio de pesquisa com especialistas (Leal Jr e D’Agosto, 2011) e estão apresentados na Tabela 1.

Com base em Rodrigues (2007), Odebrecht (2007), CETESB (2008), Gama (2008), Lopes e Ferreira (2004) e TRANSPETRO (2008) foram obtidos dados para os indicadores e foram calculadas as medidas (Mi) de ecoeficiência para cada alternativa, conforme Tabela 1. Neste caso ainda não se consideram as ações de melhoria da ecoeficiência no transporte rodoviário.

\subsection{Estudo aplicado - desempenho dos modos de transportes}

Para a normalização da Tabela 1 utilizou-se a Equação 2, pois todas as medidas adotadas preveem que quanto maiores forem os resultados dessas medidas melhor será a ecoeficiência para o sistema. Considerou-se as séries normalizadas, $\mathrm{x}_{i}{ }_{i}(k)$, com $i=0, \ldots, 10$ e $k=1, \ldots, 5$, como sendo representantes das alternativas $i$ e de suas medidas de ecoefi- ciência $k$.

Para se estabelecer uma hierarquia entre as séries calcula-se os coeficientes relacionais, por meio da Equação 4 admitindo $\zeta=0,5$ e o grau de relacionamento grey (Equação 5). Para esta aplicação considerou-se pesos iguais para todas as medidas. A Figura 3 apresenta o resultado da aplicação da técnica, já considerando a hierarquia das alternativas, onde se observa que o pior desempenho em termos de ecoeficiência ocorre para A2.

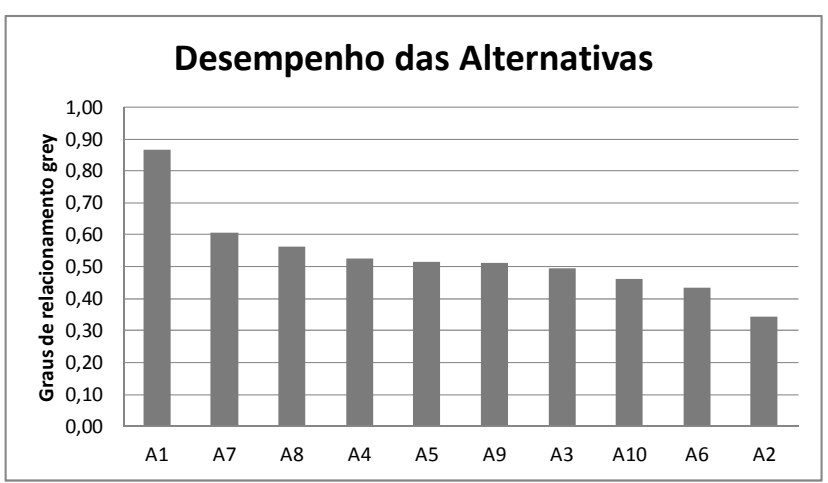

Figura 3. Classificação das alternativas de transporte

\subsection{Estudo aplicado - ações de melhoria da ecoeficiência no transporte rodoviário de cargas}

Foi realizada uma pesquisa bibliográfica para levantar possíveis ações que impactassem positivamente na ecoeficiência do transporte rodoviário (A2). Em função de limitações para obtenção de dados, a pesquisa foi feita com base nos três indicadores considerados mais importantes pelos especialistas, conforme apresentado na Tabela 2. Cabe destacar que as ações de redução de consumo de combustível tem ação direta na redução de $\mathrm{CO} 2$, apesar de estarem apresentadas separadamente na Tabela 2 .

No que se refere às ações de base tecnológica orientadas para a redução do consumo total de energia, entende-se que para os conjuntos bitrem-tanque, considerados no estudo aplicado, é prática o uso de motor turbo alimentado e pneus radiais, já estando os benefícios destas ações considerados nos valores de consumo utilizados originalmente. Ações 
como o uso de ventilador do motor com acionamento intermitente, aprimoramento no turbo compressor, uso de $\mathrm{VAV}$, uso de sistema de pós-tratamento de gases de descarga com arrefecimento avançado, eletrificação dos acessórios, redução das perdas por fricção no sistema de propulsão e uso de transmissão automatizada em veículos apresentam benefícios marginais entre $1 \%$ e $5 \%$ e o uso de tecnologia híbrida parece ser ainda uma alternativa pouco acessível para este tipo de operação. Assim optou-se por considerar o aprimoramento do perfil aerodinâmico do veículo, com providências simples como a instalação de defletores e adotar uma redução conservadora de consumo total de energia de $8,5 \%$, metade do potencial máximo.

Das 3 ações de base gerencial consideradas na Tabela 2 para a redução do consumo total de energia, a $1^{\mathrm{a}}$ parece englobar as outras 3 e escolheu-se adotar o treinamento de

Tabela 2. Ações para redução do consumo total de energia, emissão de $\mathrm{CO}_{2}$ e custo total de acidentes - ações de ecoeficiência

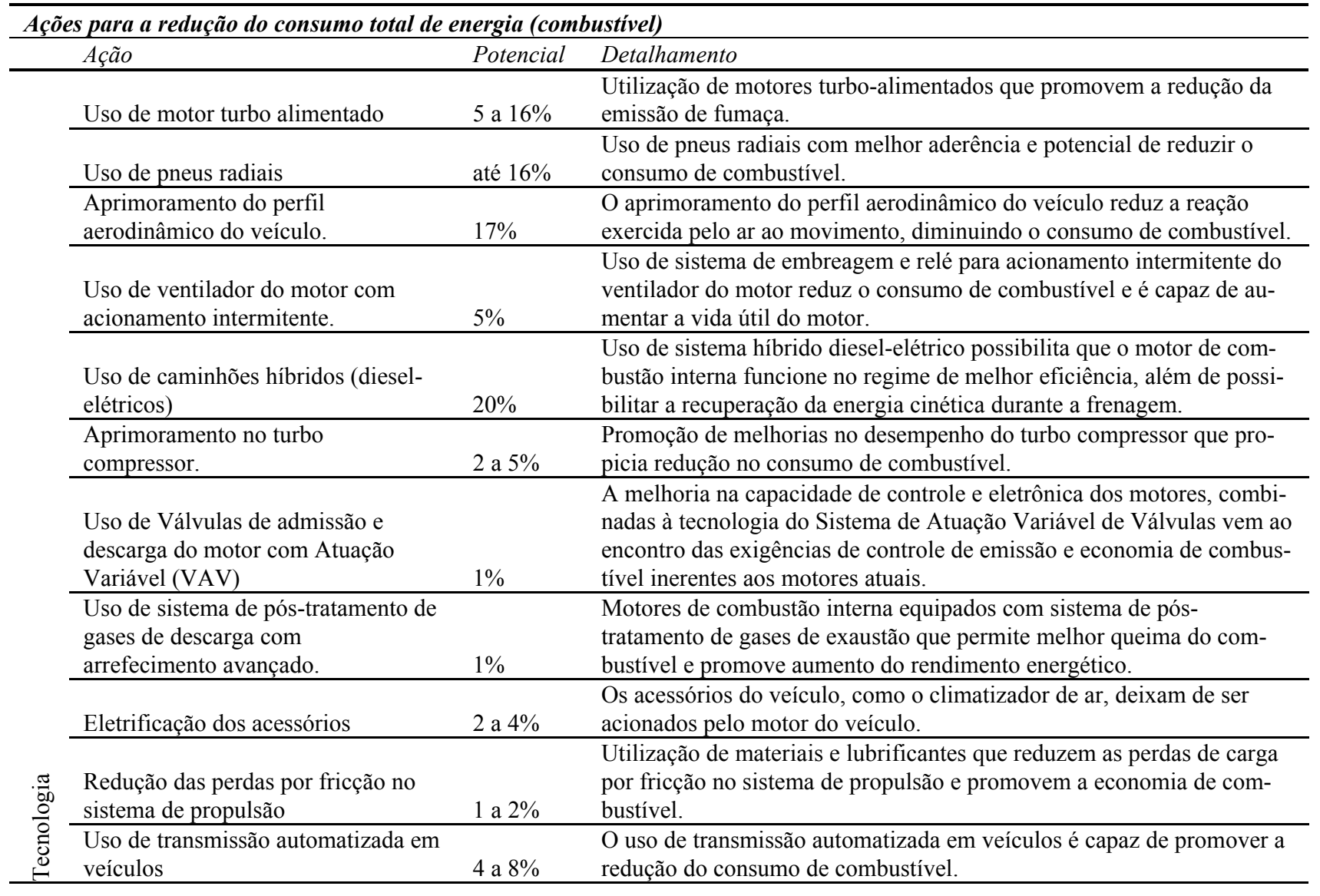

Promoção de projeto para incentivo de redução de combustível

Promoção do treinamento de motoristas

Promoção de projetos que procuram incentivar os motoristas e operadores de veículos a adotar medidas que reduzem o consumo de combustí-

Monitoramento das viagens e incentivo financeiro à motoristas Implantação de programa de conservação e manutenção de veículos vel, como o Projeto Siga Bem, EconomizAR e TransportAR.

$13 \% \quad$ combustível e com mais segurança.

Premiação aos motoristas que cumprirem as metas estabelecidas de redução de consumo de combustível que são monitoradas com a utilização de equipamento para trocas de informação em tempo real. Implantação de programa de conservação e manutenção de veículos com

foco no monitoramento e redução do consumo de combustível.

\begin{tabular}{|c|c|c|c|}
\hline & Ação & Potencial & Detalhamento \\
\hline \multirow{4}{*}{$\begin{array}{l}\frac{\pi}{60} \\
0 \\
0 \\
0 \\
0 \\
0 \\
0\end{array}$} & $\begin{array}{l}\text { Uso de caminhões híbridos (diesel- } \\
\text { elétricos) }\end{array}$ & $30 \%$ & $\begin{array}{l}\text { Uso de sistema híbrido diesel-elétrico possibilita que o motor de } \\
\text { combustão interna funcione no regime de melhor eficiência, além de } \\
\text { possibilitar a recuperação da energia cinética durante a frenagem. }\end{array}$ \\
\hline & $\begin{array}{l}\text { Uso de motores com gerenciamento } \\
\text { eletrônico }\end{array}$ & $30 \%$ & $\begin{array}{l}\text { O uso deste tipo de motor consome menos combustível, por conseguinte } \\
\text { emite menos poluentes atmosféricos, apresenta menor demanda por } \\
\text { manutenção e maior vida útil que os demais. }\end{array}$ \\
\hline & Uso de biocombustíveis & 70 a $80 \%$ & $\begin{array}{l}\text { Ao crescer, os insumos que são usualmente utilizados para produzir os } \\
\text { bicombustíveis capturam o } \mathrm{CO}_{2} \text { emitido durante sua queima. }\end{array}$ \\
\hline & $\begin{array}{l}\text { Aprimoramento do perfil } \\
\text { aerodinâmico do veículo. }\end{array}$ & $17 \%$ & $\begin{array}{l}\mathrm{O} \text { aprimoramento do perfil aerodinâmico do veículo reduz a reação } \\
\text { exercida pelo ar ao movimento, diminuindo o consumo de combustível e } \\
\text { consequente redução da emissão de } \mathrm{CO}_{2} \text {. }\end{array}$ \\
\hline
\end{tabular}


Tabela 2. Ações para redução do consumo total de energia, emissão de $\mathrm{CO}_{2}$ e custo total de acidentes - ações de ecoeficiência (continuação)

\begin{tabular}{|c|c|c|c|}
\hline \multicolumn{4}{|c|}{ Ações para a redução na emissão de gases de efeito estufa $\left(\mathrm{CO}_{2}\right)$} \\
\hline & $A c ̧ \tilde{a} o$ & Potencial & Detalhamento \\
\hline \multirow{3}{*}{ 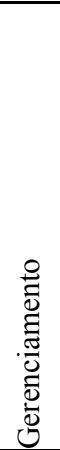 } & $\begin{array}{l}\text { Promoção de projetos de incentivo a } \\
\text { redução da poluição atmosférica }\end{array}$ & $5 \%$ a $32 \%$ & $\begin{array}{l}\text { Promoção de projetos que procuram incentivar os motoristas e operadores } \\
\text { de veículos a adotar medidas que reduzem a emissão de poluentes } \\
\text { atmosféricos pelos motores dos veículos, como o Projeto Siga Bem, } \\
\text { EconomizAR e TransportAR. }\end{array}$ \\
\hline & $\begin{array}{l}\text { Promoção de programas de } \\
\text { renovação da frota }\end{array}$ & $18 \%$ & $\begin{array}{l}\text { São programas que procuram promover a renovação da frota de veículos } \\
\text { em períodos planejados antes da deterioração parcial do veículo que possa } \\
\text { prejudicar o seu funcionamento e contribuir de forma negativa com a } \\
\text { emissão de } \mathrm{CO}_{2} \text {. }\end{array}$ \\
\hline & $\begin{array}{l}\text { Implantação de programas de } \\
\text { inspeção técnica veicular }\end{array}$ & 7 e $8 \%$ & $\begin{array}{l}\text { São programas que promovem a inspeção dos veículos em busca de falhas } \\
\text { em diferentes itens. Deve ser realizada por técnicos com certificação e } \\
\text { segue normas e padrões. Englobam a verificação de gases de escapamento } \\
\text { de motores e ruído do escapamento. }\end{array}$ \\
\hline
\end{tabular}

\section{Ações para a redução no custo total de acidentes (diminuição do índice de acidentes)} Ação Potencial Detalhamento

Alguns caminhões novos já vêm com um sistema inteligente que avisa o condutor do seu nível de fadiga, evitando que o motorista dirija com

Uso de detector de fadiga $10 \%$ sonolência e cansaco. Uso de sistema de frenagem que evita derrapagem e perda de controle do

\begin{tabular}{|c|c|c|}
\hline \multirow{3}{*}{ 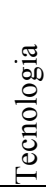 } & Uso de freio com ABS & $4 \%$ \\
\hline & Monitoramento das viagens & 5 a $10 \%$ \\
\hline & Uso de faróis de xenon & $3 \%$ \\
\hline
\end{tabular}
veículo.

O monitoramento das viagens com utilização de GPS possibilita a visualização da forma como o motorista está conduzindo o veículo. Os faróis de xênon garantem melhor iluminação através de um tipo de lâmpada incandescente com luz branca azulada.

Implantação de inspeção técnica veicular Inspeção que busca e repara falhas nos veículos. É necessária para melhor funcionamento e conservação, evitando acidentes potenciais que podem ocorrer devido às falhas mecânicas.

A imprudência e a velocidade incompatível com o trecho são os fatores que causam acidentes com veículos de carga. $\mathrm{O}$ treinamento e a maior

Promoção do treinamento de motoristas capacitação do motorista podem evitar que estes tipos de falhas não venham ocorrer durante as viagens.

Segundo a ANIP (2006) uma pesquisa realizada pela Michelin na França mostrou que pneus mal calibrados era fator de causa de acidentes com

Adoção da calibração correta dos pneus 6\% veículos. Planejar a rota por onde o caminhão vai transitar escolhendo vias seguras, sinalizadas, com iluminação adequada e principalmente com o pavimento em bom estado.

Planejamento da rota $\quad 35 \%$ Pesquisas realizadas em rodovias portuguesas mostram que estudos para

Aplicação de correções às distânrealizar medição de distâncias de visibilidade ajudam a estabelecer limites cias de visibilidade 10 e $67 \%$ de velocidade apropriados principalmente no caso de interseções de vias.

Aplicação de superfície côncava em vias e acostamentos de alta resistência à derrapagem em trechos com curvas fechadas

Medida efetiva em combate à acidentes que melhora os trechos com $15 \% \quad$ curvas perigosas quanto a possibilidade de ocorrência de acidentes. Estudos realizados no mundo inteiro mostram que a iluminação, se

Iluminação apropriada em trechos perigosos adequada, reduz o índice de acidentes, principalmente próximo a pontes e

Duplicação das vias em trechos perigosos 50 a $75 \%$ interseções de vias. Duplicar as faixas em trechos de ultrapassagensperigosas facilitam as manobras pelo condutor, diminuindo a probabilidade de acidentes. Estender a zona-livre, ou seja, o trecho da estrada onde não há obstáculos Aumento da extensão da zona-livre $\quad 44 \% \quad$ reduz acidentes.

Aplicação de medidas de canalização do tráfego Estudos apontam resultados com o "escoamento" do tráfego rodoviário

Substituição de cruzamento em X

por cruzamentos desfasados $\quad 60 \%$ para vias alternativas.

vés de ilhas direcionais e separadores

$25 \% \quad \begin{aligned} & \text { Estudos apontam resultar } \\ & \text { para vias alternativas. }\end{aligned}$

Cruzamento desfasado corresponde a dois entroncamentos (interseccões em T), situados em direções opostas e ligeiramente desencontrados.

Implantação de radares e Ð limitadores de velocidade 14 a $90 \%$ acidentes.

Desestimular as ultrapassagens em locais próximos às interseções. Em países europeus foram implantados radares e limitadores de velocidade que contribuíram significativamente com a redução de

Fonte: ANIP (2006), Gottlieb (2007), Russi Filho (2007), Seco et. al. (2008), Secretaria de Estado dos Transportes de São Paulo (2006), CNT (2009), Leal Jr (2010), ANP (2009), Oliveira e Leal Jr (2009). 
motoristas como opção a ser testada por incidir diretamente sobre uma peça chave da operação, o condutor do veículo, e possibilitar uma consciência operacional que também poderia ajudar na redução dos acidentes. Neste caso também se adotou uma redução conservadora, metade do potencial máximo, de 7,5\%. A Figura 4 apresenta o desempenho de A2 em relação às demais alternativas, após redução de $16 \%$ do consumo de energia, provenientes da instalação de defletores e adoção de treinamento a motoristas. Neste caso, além da redução no consumo de combustível fóssil considerou-se a mesma redução nas emissões de $\mathrm{CO}_{2}$ e nos poluentes atmosféricos. Em função dos possíveis gastos com a implantação dessas ações considerou-se um aumento de 3\% na receita de $\mathrm{A} 2$, de forma que esta se iguala à alternativa de maior receita - A10. Observa-se que praticamente não houve melhora no desempenho de A2, continuando esta em último lugar no ranking.

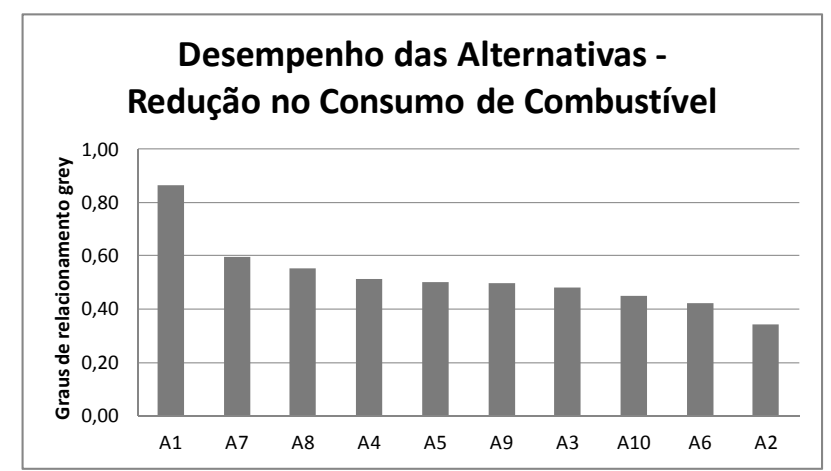

Figura 4. Classificação das alternativas de transporte após redução no consumo de energia em A2

No caso das ações aplicadas a redução das emissões de $\mathrm{CO}_{2}$, aquela que está mais alinhada as estratégias brasileiras e a que apresenta o melhor resultado médio em relação à ecoeficiência é o uso de biocombustíveis, e considerou-se a utilização de biodiesel (B100) proveniente do óleo de soja em uma frota dedicada ao transporte de etanol. A Tabela 3 mostra que, com a utilização desse combustível, é possível a redução da emissão de $\mathrm{CO}_{2}$ e dos poluentes atmosféricos considerados no estudo, com exceção do $\mathrm{NO}_{\mathrm{x}}$, que apresenta um aumento de aproximadamente $10 \%$.

Observa-se que todas as fontes consultadas tratam de B100 de rota metílica. Uma parte do $\mathrm{CO}_{2}$ não é evitada (só reduz $78 \%$ ), pois ele utiliza metanol produzido por craqueamento do carvão ou por síntese do gás natural.

A redução do enxofre aparece como $100 \%$ em três das quatro fontes utilizadas. Os $2 \%$ a menos de enxofre citados por Oliveira e Costa (2001) podem estar relacionados a resíduo de catalisador ou a metanol (ruim) de carvão, que contém muito enxofre

Como o biodiesel é éster (oxigenado) e não hidrocarbo- neto (como é o diesel) há uma tendência da queima oxidar melhor o $\mathrm{CO}$, gerando menos $\mathrm{CO}$ e mais $\mathrm{CO}_{2}$. Esse último é $78 \%$ de origem vegetal (óleo de soja), logo não contribui tanto quanto o óleo diesel para o efeito estufa (aquecimento global). Por oxidar melhor os resíduos da combustão e não conter enxofre há uma tendência de redução de MP.

Por ser de um único tipo de óleo (soja) e ser produzido na mesma rota (metílica), esse combustível tende a apresentar uma composição homogênea entre as experiências, o que possibilita a sua comparação.

Aplicando as alterações nos poluentes e nos gases em A2, observa-se uma melhoria de desempenho nessa alternativa. O grau de relacionamento grey passa de 0,34 para 0,49, saindo do último lugar em desempenho para a quinta posição no ranking, conforme Figura 5. Observa-se que neste caso também foi considerado o aumento de $3 \%$ na receita de A2.

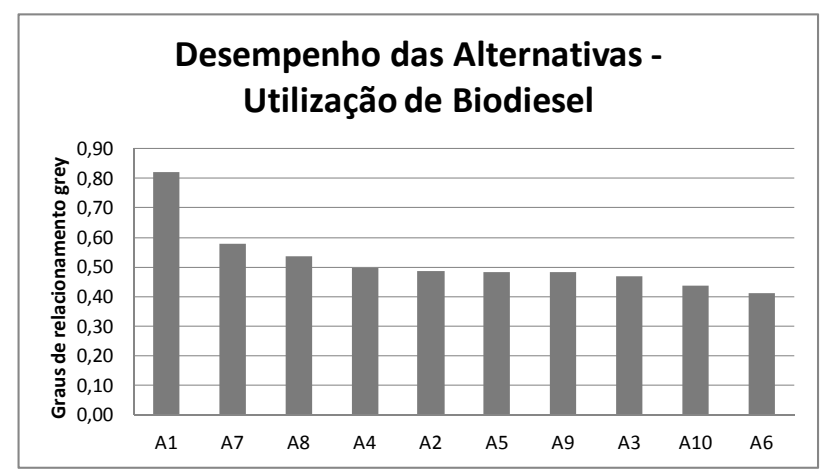

Figura 5. Classificação das alternativas de transporte após utilização de biodiesel em A2

Buscando um melhor resultado de A2, avaliou-se o desempenho considerando redução nos acidentes tomando-se como referência o Pacto Rodoviário Mineiro que prevê a redução de 40\% nos índices de acidentes com veículos de carga no Estado de Minas Gerais (Pamcary, 2010). O percentual de redução do Pacto Rodoviário Mineiro se aproxima do valor médio de ações para redução de acidentes apresentadas na Tabela 2 , que é de $36 \%$ e é a maior média comparando com os outros grupos de ações pesquisados. Aqui também foi incluído o aumento de $3 \%$ na receita de A2. A Figura 6 mostra os resultados obtidos com a aplicação desta ação.

Apesar de uma pequena melhora no desempenho de A2, saindo de 0,34 para 0,38 , não houve alteração na colocação desta alternativa em relação às demais.

Considerando um transportador rodoviário que possa ter uma frota mais eficiente, foi avaliada a adoção das ações selecionadas anteriormente de forma conjunta: redução do consumo total de energia em 16\%; utilização de biodiesel (B100); aumento de 3\% na receita e redução no índice de

Tabela 3. Alterações nas emissões de poluentes atmosféricos e $\mathrm{CO} 2 \mathrm{com}$ a utilização de biodiesel proveniente de soja

\begin{tabular}{lrrrrc}
\hline Fonte(1) & NOx & \multicolumn{1}{c}{$\boldsymbol{M P}$} & \multicolumn{1}{c}{$\boldsymbol{S O} \boldsymbol{x}$} & $\boldsymbol{C O}$ & $\mathbf{C O}_{2}$ \\
\hline Oliveira e Costa (2001) & $13,0 \%$ & $-50,0 \%$ & $-98,0 \%$ & & $-78,0 \%$ \\
Silva (2007) & & $-32,0 \%$ & $-100,0 \%$ & & $-78,5 \%$ \\
USDA e USDOE (1998) & $8,9 \%$ & $-68,1 \%$ & $-100,0 \%$ & $-46,2 \%$ & $-78,5 \%$ \\
Pacific Biodiesel (2000) & $10,0 \%$ & $-68,0 \%$ & & $-67,0 \%$ & \\
EPA (2002) & $10,0 \%$ & $-47,0 \%$ & $-100,0 \%$ & $-48,0 \%$ & \\
Média & $10,5 \%$ & $-53,0 \%$ & $-99,5 \%$ & $-53,7 \%$ & $-78,3 \%$ \\
\hline Nota: (1) todas as fontes tratam de B100 e biodiesel à base de soja. & &
\end{tabular}

Fonte: Elaboração Própria (2011) 


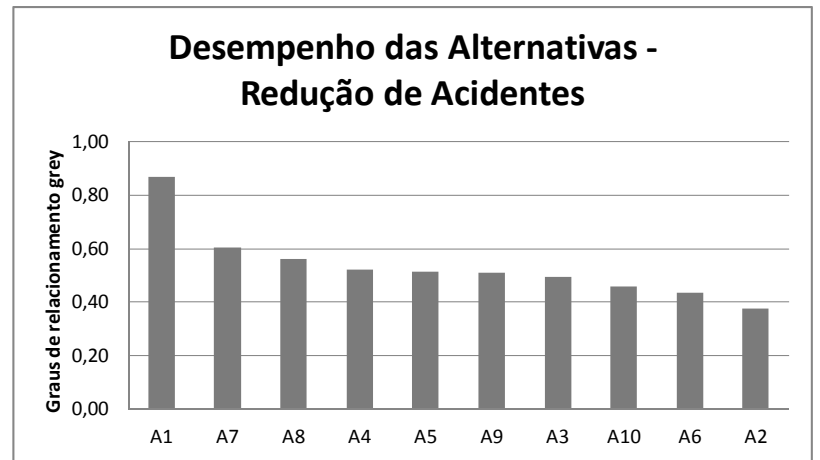

Figura 6. Classificação das alternativas de transporte após redução de acidentes em A2

acidentes em $40 \%$. Com essas ações apenas em A2 tem-se novos valores das respectivas medidas conforme Tabela 4.

Os resultados da aplicação do MEM e GRA com os novos valores dos indicadores, provenientes da implementação de ações de melhoria da ecoeficiência estão na Figura 7.

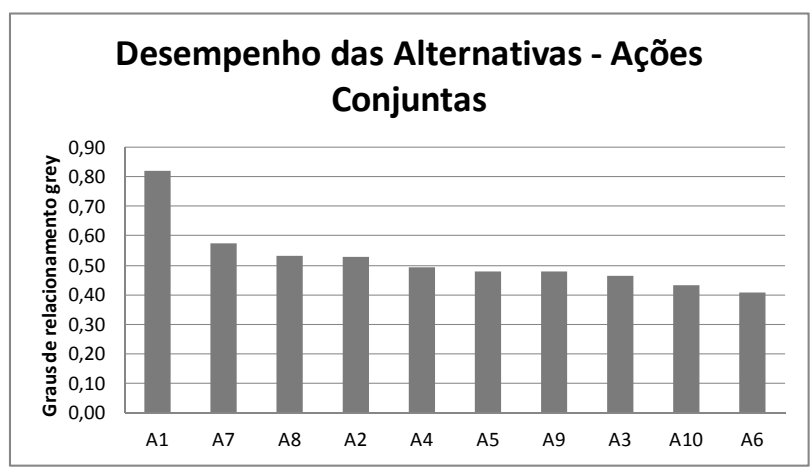

Figura 7. Desempenho das alternativas com a adoção de ações para melhoria de $\mathrm{A} 2$

Analisando a Figura 4, é possível constatar uma melhoria no desempenho de A2, que saltou do último lugar na avaliação original para o quarto lugar, tendo o desempenho muito próximo de A7 e A8.

Com os resultados obtidos é possível constatar que considerando as ações de forma isolada, a que apresenta os me- lhores resultados é a utilização de biodiesel (B100). Além disto, é a ação que demanda menores esforços de implantação por parte dos transportadores visto que já há tecnologia de produção desenvolvida e valores de compra acessíveis para este combustível. Basta deixar de utilizar óleo diesel e passar a usar o biodiesel.

Ações de redução de consumo de energia (instalação de defletores e treinamento de motoristas) demandam esforços e gastos maiores e de forma isolada não produzem efeitos no desempenho do transporte rodoviário.

Já com relação à redução de acidentes há um resultado pouco expressivo de desempenho se comparado ao grau de mobilização dos setores público e privado e os custos de implantação das ações disponíveis.

Observa-se que a utilização de biodiesel (B100) se destaca positivamente na possibilidade de melhoria de desempenho em A2 mesmo se comparada à utilização conjunta das ações abordadas neste estudo, sendo uma ação isolada que produz um efeito equivalente ao conjunto de ações Além disso, tais ações parecem ser aquelas que apresentam os melhores potenciais de melhoria da ecoeficiência desta atividade a luz da Tabela 2, o que reforça a escolha do uso do B100 neste contexto.

\section{CONCLUSÃO}

Os resultados mostram que mesmo a alternativa de pior desempenho pode ser melhorada se ações relacionadas à gestão ou melhoria de tecnologia forem implementadas. Observa-se que as ações propostas são de possível adoção, cabendo aos transportadores, governo e embarcadores realizarem parcerias para viabilização das mesmas. Cita-se, por exemplo, um grupo investidor que queira desenvolver uma transportadora com as características das melhorias simuladas neste trabalho para competir no mercado de transporte de etanol.

A melhoria de desempenho do modo rodoviário poderia ser potencializada, considerando que essa alternativa é a que possui menor número de transbordos, o que corresponde a menor tempo de percurso e possibilita melhor atendimento ao cliente que valoriza esse atributo.

Tabela 4. Medidas com a implementação de ações de ecoeficiência em conjunto

\begin{tabular}{|c|c|c|c|c|c|}
\hline & M1 & $M 2$ & M3 & M4 & M5 \\
\hline & $\begin{array}{l}R F R / C T A \\
\text { (receita de frete } \\
\text { recebida }- \text { RFR; } \\
\text { custo total de } \\
\text { acidentes }-C T A \text { ) } \\
\text { [Adimensional] }\end{array}$ & $\begin{array}{l}R F R / C T E \\
\text { (receita de frete } \\
\text { recebida }- \text { RFR; } \\
\text { consumo total de } \\
\text { energia }- \text { CTE) } \\
{[U S \$ / M J]}\end{array}$ & $\begin{array}{l}R F R / C O 2 E \\
\text { (receita de frete } \\
\text { recebida - RFR; } \\
\text { emissão de gases } \\
\text { de efeito estufa- } \\
C O 2 E \text { ) } \\
\text { [US\$/kg] }\end{array}$ & $\begin{array}{l}R F R / P A E \\
\text { (receita de frete rece- } \\
\text { bida - RFR; emissão } \\
\text { de poluentes atmosfé- } \\
\text { ricos }- \text { PAE) } \\
{[U S \$ g]}\end{array}$ & $\begin{array}{l}\text { RFR/QOMD } \\
\text { (receita de frete } \\
\text { recebida-RFR; } \\
\text { óleo lubrificante } \\
\text { descartado- } \\
\text { QOMD) } \\
{[U S \$ / l]}\end{array}$ \\
\hline Alternativas & $x_{i}^{(0)}(1)$ & $x_{i}^{(0)}(2)$ & $x_{i}^{(0)}(3)$ & $x_{i}^{(0)}(4)$ & $x_{i}^{(0)}(5)$ \\
\hline A1 & 32,03 & 0,19 & 3,49 & 41,27 & 5404,63 \\
\hline $\mathrm{A} 2$ & 86,12 & 0,07 & 3,85 & 24,71 & 1310,42 \\
\hline A3 & 107,07 & 0,12 & 1,70 & 20,70 & 2401,47 \\
\hline A4 & 103,90 & 0,14 & 1,98 & 23,81 & 2733,34 \\
\hline A5 & 73,12 & 0,16 & 2,30 & 28,14 & 2214,44 \\
\hline A6 & 97,30 & 0,10 & 1,37 & 17,18 & 1633,57 \\
\hline A7 & 121,37 & 0,16 & 2,21 & 26,77 & 2630,57 \\
\hline A8 & 124,14 & 0,13 & 1,83 & 22,51 & 2307,42 \\
\hline A9 & 82,21 & 0,15 & 2,12 & 25,42 & 2941,54 \\
\hline A 10 & 97,74 & 0,11 & 1,56 & 19,19 & 2251,63 \\
\hline$x_{0}{ }^{(0)}(j)$ & 124,14 & 0,19 & 3,49 & 41,27 & 5404,63 \\
\hline
\end{tabular}


A utilização de biodiesel parece ser a ação (das que foram testadas) mais promissora tanto em viabilidade financeira quanto operacional, demonstrando que são válidos os esforços feitos no país para o desenvolvimento e produção deste combustível.

Existem algumas limitações no trabalho relacionadas aos dados utilizados, sendo a maioria levantada por meio de estimativas. Outra limitação refere-se a quantidade de biodiesel disponível no mercado que pode, atualmente, ainda não ser suficiente para utilização do B100.

Como proposição para novos estudos recomenda-se o levantamento dos custos para a implementação de ações como melhoria da ecoeficiência. Poderiam ser utilizados outros indicadores e medidas incluindo outras influências ambientais não contempladas neste estudo e ainda poderiam ser testadas outras combinações de ações para melhoria da ecoeficiência.

Seria possível testar também a inclusão de redução de consumo de óleo lubrificante com melhoria de manutenção o que não foi feito neste trabalho por falta de dados adequados. Por fim, a utilização da análise relacional grey com a utilização de pesos nas medidas poderia trazer outros resultados na avaliação, representando a realidade de um grupo decisor.

\section{REFERÊNCIAS BIBLIOGRÁFICAS}

ANIP (2006) Associação Nacional da Indústria de Pneumáticos - I Seminário sobre segurança nas rodovias. Ministério dos Transportes, Secretaria de Política Nacional de Transportes.

ANP (2009) Anuário Estatístico 2009. Agência Nacional do Petróleo, Gás Natural e Biocombustíveis. Brasil.

Antoniolli, P. D. (2003) Medidas de Desempenho em Gerenciamento da Cadeia deSuprimentos. Anais do XXIII Encontro Nacional de Engenharia de Produção, Ouro Preto, Minas Gerais: ABEPRO.

ANTT (2008) Agência Nacional De Transportes Terrestres. Disponível em: <http://www.antt.gov.br>. (Acesso em 30/05/2008).

Ballou, R. H. (2001) Gerenciamento da Cadeia de Suprimentos. Porto Alegre, Bookman.

Becken, S. (2007) Developing indicators for managing tourism in the face of peak oil. Tourism Management, v. 29, n. 4, p. 695-705. DOI 10.1016/j.tourman.2007.07.012.

Bischoff, E. (2008) Estudo da utilização de algorítimos genéticos para seleção de redes de acesso. Dissertação (mestrado). Departamento de Engenharia Elétrica. Universidade de Brasília, Brasília.

Bowersox, D. e D. Closs (2001) Logística Empresarial. São Paulo: Atlas, Tradução de: Logistical management: the integrated supply chain process.

Britsh Petroleum - BP (2003) Relatório anual 2003. Disponível em $<$ www.bp.com>. (Acesso em 01/10/2011).

Cantarino, A. A. A. (2003) Desenvolvimento de indicadores de impacto ambiental como instrumento de gestão e controle no processo de licenciamento ambiental e empreendimento ambiental de exploração de produtos nas áreas Offshore. Tese (Doutorado). PPE/COPPE/UFRJ, Rio de Janeiro.

CEBDS (2008) Conselho Empresarial Brasileiro para o desenvolvimento sustentável. Disponível em: <http://www.cebds.org.br/cebds/ecorbe-beneficios.asp>. (Acesso em16/04/2008).

CETESB (2009) Estatísticas de Acidentes Ambientais. Companhia de Tecnologia e Saneamento Ambiental. Internet, Disponível em $<$ http://www.cetesb.sp.gov.br/emergencia/estatisticas/estatisticas. pdf $>$. (Acesso em 02/11/2009).

Cheon, S.; D. E. Dowall e D. Song (2009) Evaluating impacts of institutional reforms on port efficiency changes: Ownership, corporate structure, and total factor productivity changes of world container ports. Transportation Research Part E, v. 46, n. 4, p. 546-561. DOI:10.1016/j.tre.2009.04.001

Chopra, S. e P. Meindl (2003) Gerenciamento da Cadeia de Suprimentos Estratégia, Planejamento e Operação. São Paulo, Prentice Hall.

Christopher, M. (1997) Logística e Gerenciamento da Cadeia de Suprimentos: Estratégia para redução de custos e melhoria dos serviços. São Paulo: Pioneira.
CNT (2007) Boletim Estatístico CNT. Confederação Nacional do Transporte. Internet; Disponível em: $<$ http://www.cnt.org.br/Imagens $\% 20 \mathrm{CNT} / \mathrm{PDFs} \% 20 \mathrm{CNT} /$ Boletim $\% 20$ Estat $\% \mathrm{C} 3 \%$ ADstico/Boleti mEstatistico.Nov.2007.pdf> (Acesso em 15/04/2011).

D'Agosto, M. A. e S. K. Ribeiro (2004) Eco-efficiency management program (EEMP) - a model for road fleet operation. Transportation Research Part D: Transport and Environment, v. 9, n. 6, p. $497-$ 511. DOI:10.1016/j.trd.2004.09.001.

D’Agosto, M. A. (1999) Avaliação do Desempenho Operacional de Sistemas deTransportes Urbanos em Vias Segregadas. Dissertação (Mestrado). Instituto Militar de Engenharia, Rio de Janeiro, RJ, Brasil.

Deng, J. (1989) Introduction to grey system theory. Journal of Grey Systems, v. 1, p. 1-24.

Dreyer, D. E. (2000) Performance measurement: a practitioner's perspective. Supply Chain Management Review, v. 4, n. 4, p. 63-68.

English, M., Castellucci, M. and Mynors, D.J. (2006) Eco-efficiency of the cold roll formed product supply chain. Journal of Materials Processing Technology, v. 177, p. 626-629. DOI: 10.1016/ i.jmatprotec.2006.03.178.

EPA (2002) A Comprehensive Analysis of Biodiesel Impacts on Exhaust Emissions. U.S. Environmental Protection Agency. EPA-Draft Technical Report, EPA420- P-02-001, October 2002.

Fontana, A.; P. Faria; M. E. P. Moreira e N. G. S. D. Montenegro (2009) Escolha do modal com maior índice socioeconômico ambiental para o transporte de soja a granel entre Cuiabá-MT e SantarémPA. Anais do XXII ANPET - Congresso de Pesquisa e Ensino em Transportes, Vitória, ES.

Frota Neto, J. Q; G. Walther; J. Bloemhof; J. A. E. E. Nunen e T. Spengler (2009) A methodology for assessing eco-efficiency in logistics networks, European Journal of Operational Research, v. 193, n. 3, p. 670-682. DOI:10.1016/j.ejor.2007.06.056.

Gama, R B. (2008) A decisão entre os modos rodoviário e ferroviário no transporte dos bens siderúrgicos visando a eco-eficiência. UFF. Monografia, Escola de Ciências Humanas e Sociais. Volta Redonda, RJ.

GLOBAL REPORTING INITIATIVE - GRI (2000) Sustainable Reporting Guidelines on Economic, Environmental and Social Performance. In: Global Reporting Initiative, p. 16-18, Boston, USA. June.

Gonçalves, B. S. e M. B. B. Costa (2009) Tomada de decisão em nível estratégico entre transporte rodoviário ou transporte intermodal para o escoamento de carga geral no Brasil. In: Anais do XXII ANPET Congresso de Pesquisa e Ensino em Transportes, 2009, Vitória, ES.

Gottlieb, P. C. (2007) Engenheiro mecânico - Inspeção Técnica Veicular. Campanha de Segurança no Trânsito.

Graneman, S. R. e I. R. Gartner (2000) Modelo Multicriterial para Escolha Modal/Sub-Modal de Transporte. Anais do XIV Congresso de Pesquisa e Ensino em Transportes - ANPET, Gramado, p. 337 345.

Hendriks, C. e D. Jager (2001) Economic Evaluation of Sectoral Emission Reduction Objectives for Climate Change: Economic Evaluation of Methane Emission Reduction in the Extraction, Transport and Distribution of Fossil Fuels in the EU. European Commission Studies, Holanda. Disponível em: <http://ec.europa.eu/ environment/enveco/climate_change/pdf/fossilfuel.pdf $>$. (Acesso em 01/10/ 2011).

Holliday, C. O. e S. W. P. Schmidheing (2003) Cumprindo o Prometido: Caso de Desenvolvimento Sustentável. Ed. Campus, 1 ed., Rio de Janeiro. Disponível em: <http://www.anp.gov.br/?pg=8240\&m= $\& \mathrm{t} 1=\& \mathrm{t} 2=\& \mathrm{t} 3=\& \mathrm{t} 4=\& \mathrm{ar}=\& \mathrm{ps}=\&$ cachebust $=1258834614687>$. (Acesso em 01/02/2009).

Jollands, N.; J. Lermit e M. Patterson (2004) Aggregate eco-efficiency indices for New Zealand-a principal components analysis. Journal of Environmental Management, v. 73, p. 293-305.

Lambert, D. M. e T. L. Pohlen (2001) Supply chain metrics. The International Journal of Logistics Management, v. 12, n. 1, p. 1-19.

Leal Jr, I. C. (2010) Método de escolha modal para transporte de produtos perigosos com base em medidas de ecoeficiencia. Tese (Doutorado). Programa de Pós-Graduação em Engenharia de Transportes, COPPE, UFRJ, Rio de Janeiro.

Leal Jr, I. C. e M. A. D'Agosto (2011) Modal choice for transportation of hazardous materials: the case of land modes of transport of bioethanol in Brazil. Journal of Cleaner Production, v. 19, p. 229 240. DOI:10.1016/j.jclepro.2010.02.006. 
Leal Jr, I. C. e M. A. S. Macedo (2004) Avaliação de Desempenho na Cadeia de Suprimentos In: VII Simpósio de Pesquisa Operacional e Logística da Marinha, Rio de Janeiro.

Leyen, B. C. (2008) Eco-eficiência na exploração e produção de petróleo e gás em regiões de florestas tropicais úmidas: o caso da Petrobrás na Amazônia. Dissertação (Mestrado). COPPE/UFRJ, Rio de Janeiro.

Liu, S e Y. Lin (2006). Grey information: theory and practical applications. Springer, London.

Lopes, M. S. e J. C. F. Ferreira (2004) Viabilidade de operação do transporte decontêineres nas hidrovias Tietê-Paraná e Paraguai. Anais da XVIII SOBENA, Rio de Janeiro - RJ,

Manhein, L. M. (1980). Understanding Supply in Transportation Systems. Transportation Research. v. 14, n. 2, p. 119-135. DOI: 10.1016/0191-2607(80)90111-9.

Martins, R. S.; D. S. Lobo e S. M. Pereira (2005) Atributos relevantes no transporte de granéis agrícolas: preferência declarada pelos embarcadores. Revista de Economia e Agronegócio, v.3, n. 2, p. 173-192.

Mello, P. F. B.; B. C. Cardoso e M. A. D’Agosto (2009) Identificação dos atributos de desempenho para a utilização do serviço de transporte de carga pela hidrovia tietê-paraná. In: Anais do XXII ANPET Congresso de Pesquisa e Ensino em Transportes, 2009, Vitória, ES.

Michelini, A. N. C.; R. F. Jappur; P. M. Selig e A. A. Leripio (2004) Uma proposta de incorporação de indicadores de ecoeficiência ao setor termoelétrico brasileiro a carvão mineral. In: XXIV Encontro Nac. de Eng. de Produção, Florianópolis, SC, Brasil. Disponível em: $<$ http://www.abepro.org.br/biblioteca/enegep2004_enegep1003_1 413.pdf $>$. (Acesso em 01/12/2011).

Michelsen, O; A. M. Fet e A. Dahlsrud (2005) Eco-efficiency in extended supply chains: A case study of furniture production. Journal of Environmental Management, v. 79, n. 3, p. 290-297. DOI: 10.1016/j.jenvman.2005.07.007.

Mickwitz, P.; M. Melanen; U. Rosenstro e J. Seppala (2005) Regional ecoefficiency indicators e a participatory approach. Journal of Cleaner Production, v. 14, n. 18, p. 1603 - 1611. DOI:10.1016/ j.jclepro.2005.05.025.

Morlok, E. K. (1980) Types of Transportation Supply Functions and TheirApplications. Transportation Research. v. 14, p. 9-27. DOI: 10.1016/0191-2615(80)90030-2.

Neves, J. C. S. (2000) Aplicação da Análise Envoltória de Dados (DEA) Para Avaliação de Fornecedores. Tese (Mestrado em Sistemas e Computação) - Instituto Militar de Engenharia.

Novaes, A. G. (2004) Logística e Gerenciamento da Cadeia de Distribuição. Campus, Rio de Janeiro.

ODEBRECHT (2007) A Logística do Etanol - Perspectivas dos Produtores. Disponível em: <http://www.anebrasil.org.br/periodico/ Logistica\%20do\%20Etanol.pdf>. (Acesso em 05/06/08)

Odum, E. P. (1998) Ecologia. Editora Guanabara, Rio de Janeiro.

Oliveira, L. B. e A. O. Costa (2001) Biodiesel: uma experiência de desenvolvimento sustentável. IVIG/COPPE/UFRJ, Rio de Janeiro, 2001. Disponível em: <http://www.ivig.coppe.ufrj.br/doc/ biodiesel.pdf>. (Acesso em 30/03/2007).

Oliveira, R. L. M. e M. V. Q. Cury (2004) A escolha modal no transporte de cargas sob a ótica da modelagem neuro-fuzzy: um estudo de caso. In: Anais do XVIII ANPET - Congresso de Pesquisa e Ensino em Transportes, Florianópolis, SC.

Pacheco, E. A.; E. Drohomeretski e P. A. Cardoso (2008) A decisão do modal de transporte através da metodologia AHP na aplicação da logística enxuta: um estudo de caso. IV Congresso Nacional de Excelência em Gestão Responsabilidade Socioambiental das Organizações Brasileiras. Niterói, RJ.

Pereira Neto, W. A. (2001) Modelo Multicritério de Avaliação de Desempenho Operacional do Transporte Coletivo por Ônibus no Município de Fortaleza. Dissertação (Mestrado). Programa de Mestrado em Engenharia de Transportes, Universidade Federal do Ceará, Fortaleza.

Pereira, L. C. de S. N. (1983) Avaliação de Desempenho de Sistemas de Transporte por Ônibus. COPPE/UFRJ, Dissertação (Mestrado). Programa de Engenharia de Transportes, Rio de Janeiro.

Petrobrás (2003). Relatório anual, análise financeira e demonstrações contábeis. Petrobrás.

Pezerico, L. A. M. (2002) Sistema de avaliação de desempenho no transporte urbano: uma abordagem para o setor metroviário. Dissertação (Mestrado). Mestrado Profissionalizante em Engenharia. Escola de Engenharia, Universidade Federal do Rio Grande do Sul. Porto Alegre.
Pinho, H. M.; M. N. Catanzano e P. J. C. Candeira (2011) Ecoeficiência: um estudo de caso em uma indústria química. In: 3rd. International Workshop Advances in Cleaner Production. São Paulo, Brasil.

Quintão, R. T.; S. V. Conceição e M. F. B. Drumond (2003). Avaliação da Utilização de Indicadores Logísticos de Desempenho na Cadeia Brasileira de Suprimentos de Refrigerante. Anais do XXIII Encontro Nacional de Engenharia de Produção. Ouro Preto, Minas Gerais: ABEPRO.

Rodrigues, S. B. M. (2007) Avaliação das alternativas de transporte de etanol para exportação na região centro-sul. Dissertação (Mestrado). Escola de Engenharia de São Carlos, Universidade de São Paulo, São Carlos.

Russi Filho, D. (2007) Evolução dos sistemas de monitoramento na gerência de risco. I Seminário de gerenciamento de riscos. GRISTEC.

Saari, A.; M. Lettenmeier; K. Pusenius e E. Hakkarainen (2006) Influence of vehicle type and road category on natural resource consumption in road transport. Transportation Research Part D, v. 12, n. 1, p. 23-32. DOI:10.1016/j.trd.2006.10.005.

Salgado, V. G. (2007). Indicadores de ecoeficiência e o transporte de gás natural. Rio de Janeiro: Interciência.

Santana Filho, A. R. (1984) Avaliação de Desempenho de Serviços de Ônibus Urbano do Ponto de Vista do Usuário. Dissertação (Mestrado). Programa Engenharia de Transportes, COPPE/UFRJ, Rio de Janeiro.

Santos, D. R. (2006) O Perfil do transporte rodoviário de produtos perigosos no Distrito Federal - Uma proposta metodológica, Distrito Federal.

SCC (2002) Supply Chain Operations Reference. Supply Chain Concil Model. Versão 5.0. SCC, Pittsburgh.

Schmidt, M. e R. Schwegler (2008) A recursive ecological indicator system for the supply chain of a company. Journal of Cleaner Production, v. 16, n. 15, p. 1658-1664. DOI:10.1016/ j.jclepro.2008.04.006.

Seco E. (2008) Manual do planejamento de acessibilidades e transportes Segurança Rodoviária. Comissão de Coordenação e Desenvolvimento Regional do Norte.

SETSP (2006) Balanço anual dos transportes. Os transportes no Estado de São Paulo. Secretaria de Estado de Transportes de São Paulo, Governo de São Paulo.

Silva Neves, J. C. (2000) Aplicação da Análise Envoltória de Dados (DEA) Para Avaliação de Fornecedores. Tese (Mestrado em Sistemas e Computação) - Instituto Militar de Engenharia.

Silva, P. R. (2004) Transporte Marítimo de Petróleo e Derivados na costa Brasileira: Estrutura e Implicações Ambientais. Tese (Doutorado). COPPE, Universidade Federal do Rio de Janeiro, Rio de Janeiro.

Silva, R. R. e I. C. Leal Jr. (2009) A evolução dos indicadores de eficiência operacional da ferrovia brasileira: contexto atual e perspectivas futuras de uma empresa do setor In: Anais do XXIII ANPET Congresso de Ensino e Pesquisa em Transportes, Vitória, ES.

Silva, W. S. D. (2007) Uma avaliação de fatores para o desenvolvimento sustentável da produção de biodiesel, incluindo agricultura familiar em arranjos produtivos. Escola Politécnica da Universidade de Pernambuco. UPE - Recife - PE.

TRANSPETRO (2008) Projeto Multimodal da hidrovia Tietê-Paraná. VI. Simpósio Internacional e Mostra de Tecnologia da Agroindústria Sucroalcooleira. Piracicaba - SP.

Tsoulfas, G.T. e C. P. Pappis (2005) Environmental principles applicable to supply chains design and operation. Journal of Cleaner Production, v. 14, n. 18, p. 1593 - 1602. DOI:10.1016/ j.jclepro.2005.05.021.

Tuzkaya, U. R. e S. Önüt (2008) A fuzzy analytic network process based approach to transportation-mode selection between Turkey and Germany: A case study. Information Sciences, v. 178, n. 15, p. 3133-3146. DOI:10.1016/j.ins.2008.03.015.

USDA e USDOE (1998) Life Cycle Inventory of biodiesel and petroleum diesel foruse in a urban bus. Final Retport, May, 1998. US Departament of Energy and US Departament of Agriculture.

VALE (2007) Logística da Vale. Companhia Vale do Rio Doce. Internet, Disponível em: <http://www.revistaferroviaria.com.br/nt2007/ palestras/24-Out/FCA\%20-20Negocios\%20nos\%20trilhos.pdf>. (Acesso em 20/03/2010).

VARIG (2002) A Sustentabilidade na Empresa. Disponível em: $<$ http://www.cebds.org.br/cebds/pub-docs/relatorio-sustentabili dade/rel-2002- br/varig.pdf $>$. (Acesso em 25/04/2009).

Verfaillie, H. A. e R. Bidwell (2000) Measuring eco-efficiency - a guide to reporting company performance. World Business Council for 
Sustainable Development. Disponível em: < http://www.gdrc.org/ sustbiz/measuring.pdf $>$. (Acesso em 29/03/2010).

Walley, N. e B. Whitehead (1994) It's not easy being green. Harvard Business Review, v. 72, n. 3, p. 46-52.

WBCSD (2000) Measuring Eco-Efficiency. A Guide to Reporting Company Performance. Word Business Council for Sustainable Development, Geneva, Switzerland.

Wen, K. (2004) Grey Systems: Modeling and Prediction. Printed in USA by Yang's Scientific Press. ISBN 0-9721212-7-7.

Zuo, F. (1995) Determining Method for Grey Relational Distinguished Coefficient. A CM SIGICE Bulletin, v. 20, n. 3. Institute of Grey System Liaocheng Teachers' College Liaocheng, Shandong 252059, China. 